\title{
EXPERIMENTAL HYBRIDS BETWEEN DROSOPHILA WILLISTONI STURTEVANT AND DROSOPHILA PAULISTORUM DOBZHANSKY AND PAVAN FROM SOUTHERN MARGINAL POPULATIONS
}

\author{
HELGA WINGE and A. R. CORDEIRO \\ Departmento de Genética, Universidade do Rio Grande do Sul, \\ Pôrto Alegre, Brazil
}

Received 1.ii.62

\section{INTRODUCTION}

Notwithstanding the morphological similarity of "sibling species" (Mayr, 1942) they maintain complete reproductive isolation in nature showing that speciation might occur without morphological divergence.

The willistoni group of sibling species includes the two studied here and three others : D. equinoxialis Dobzhansky (1946), D. tropicalis Burla and da Cunha and D. insularis Dobzhansky. This is the most important group of Drosophila species in the Neotropical region. It is the best studied in several respects, for example, the mutational load, chromosomal polymorphism, comparative biochemistry, genetic effects of radiations on populations, ecology, incipient speciation, physiological characteristics. It has also one of the widest geographic distributions with highly dense wild populations in warmer seasons. Yet, Drosophila insularis Dobzhansky, the most recently described species in this group (Dobzhansky, Ehrman and Pavlovsky, 1957) was found in Lesser Antilles only.

Burla et al. (1949) found the usual taxonomic traits not reliable for identification of species in single individuals, Identification is achieved by the use of other morphological characteristics. Malogolowkin (1952) showed the usefulness of male genitalia in distinguishing these species. Nevertheless, the detailed study of disk patterns of polythenic salivary gland chromosomes remains one of the best methods of specific determination as Burla et al. (1949) suggested. However, this method and the intercrossing tests depend on the existence of fertile females and cannot be used in field work, ecology, etc. Spassky (1957) described slight but consistent difference between the external male genitalia, that allows a direct discrimination of the five sibling species. This is a helpful auxiliary method in spite of being limited to one sex.

Burla et al. (1949) obtained no hybrids between the first four known species. Dobzhansky, Ehrman and Pavlovsky (1957) discovered that $D$. insularis can produce hybrids with $D$. tropicalis and D. willistoni. This was the first instance of interspecific hybridisation in this group. Recently, Winge and Cordeiro (I 96o) have reported the first hybrids obtained between southern races of $D$. willistoni and $D$. paulistorum. It is well known that the study of interspecific hybrids 
helps in understanding actual evolutionary processes underlaying speciation. An extensive work on the affinities between all species and subspecies of the willistoni sibling group is in progress. This paper reports the experiments on sexual isolation, and the fertile hybrids obtained between a strain of $D$. paulistorum and another of $D$. willistoni.

\section{ORIGIN OF THE STRAINS}

The southernmost border of Neotropical rain forest reaches the north of the State of Rio Grande do Sul, at Torres County. Near the locality of Colônia São Pedro de Alcântara, we collected many samples of Drosophila, including those of 25th September 1959, from which the strains of willistoni and paulistorum here studied were obtained. In a total of i 80 flies, only 39 " willistoni" have been found. Each female collected was singly cultured in a vial. The 18 fertile cultures obtained have been test crossed with white virgin willistoni females from a laboratory stock, and paulistorum virgin females from Angra dos Reis (Rio de Janeiro) and Sapé (Minas Gerais). Two strains proved to be paulistorum but in further tests they produced larvæ or pupæ with three, and adults with one of the 16 willistoni strains.

\section{SEXUAL ISOLATION}

Multiple choice, crossing tests have been performed to determine the sexual isolation between the selected strains. In each culture vial $(30 \times 80 \mathrm{~mm}$.) were placed ten males of one species and ten virgin females of each species. These individuals were all identically aged for three days before mating. The virgin females were marked by clipping a slight nick in either the right or the left wing, according to the species. All experiments were conducted at $25^{\circ} \pm 0.5^{\circ} \mathrm{C}$. under diffuse natural light together with artificial "daylight fluorescence tubes" lighting during the normal day period. After IO, I5 or 20 days the females were dissected and their spermathecæ and ventral receptables examined microscopically for spermatozoa. Table I summarises the results of these three differently lasting tests of sexual isolation.

The isolation coefficients in table I have been computed using the formulæ proposed by Levene (1949). These isolation coefficients become equal to zero when no isolation is present, equal to $+I$ if isolation is complete, and they take a negative value if there are more hetero- than homogamic inseminations.

Each isolation coefficient (table $\mathrm{I}: \mathrm{K}_{1,2}$ and $\mathrm{K}_{2,1}$ ) yield a highly significant $t$ value when tested against its standard error. These coefficients also show that there is stronger sexual isolation when willistoni males are used.

The application of the test for equality of two independent coefficients of isolation (Levene, I949) disclosed significant disparity in the sexual isolation between the experiments of Io and 20 days with 


\begin{tabular}{|c|c|c|c|c|}
\hline \multirow{7}{*}{ 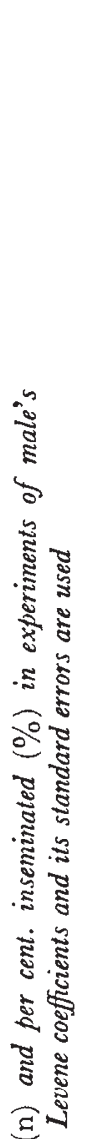 } & 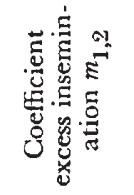 & $\begin{array}{l}0 \\
0 \\
\dot{0} \\
+1 \\
+ \\
+ \\
\dot{0}\end{array}$ & $\begin{array}{l}0 \\
0 \\
\dot{H} \\
+1 \\
0 \\
0\end{array}$ & $\begin{array}{l}\infty \\
\dot{0} \\
+1 \\
\vdots \\
\dot{0}\end{array}$ \\
\hline & 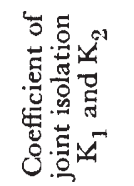 & $\begin{array}{l}0 \\
\dot{0} \\
+1 \\
\tilde{0} \\
\dot{0}\end{array}$ & $\begin{array}{l}0 \\
\dot{0} \\
+1 \\
\infty \\
\infty \\
\dot{0}\end{array}$ & $\begin{array}{l}0 \\
\dot{0} \\
+1 \\
\infty \\
0 \\
0\end{array}$ \\
\hline & 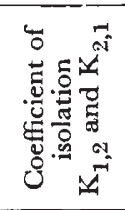 & $\begin{array}{ll}\overbrace{0} & 0 \\
\dot{0} & 0 \\
0 & 0 \\
H & H \\
0 & 0 \\
0 & 0 \\
0 & 0\end{array}$ &  & 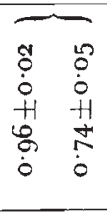 \\
\hline & \multirow{2}{*}{ 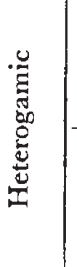 } & 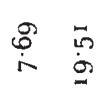 & $\begin{array}{l}\stackrel{N}{a} \\
\stackrel{a}{a}\end{array}$ & 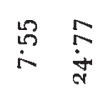 \\
\hline & & + & $\stackrel{\Xi}{\Xi}$ & $\stackrel{\circ}{\circ}$ \\
\hline & \multirow{2}{*}{ 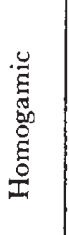 } & 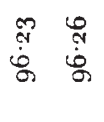 & 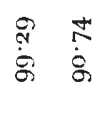 & 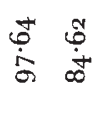 \\
\hline & & $\stackrel{\wp}{\circ}$ & $\Xi \stackrel{\infty}{\Xi}$ & a \\
\hline 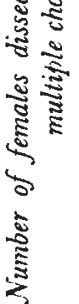 & 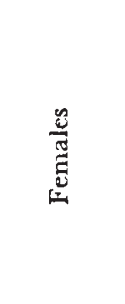 & 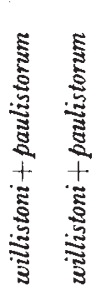 & 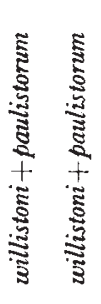 & 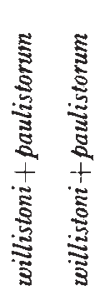 \\
\hline \multirow{2}{*}{ 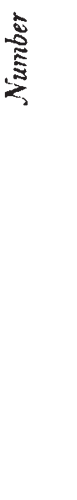 } & $\frac{\frac{\mathscr{Q}}{\pi}}{\frac{\pi}{2}}$ & 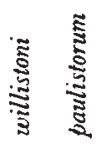 & 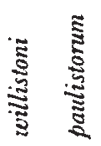 & 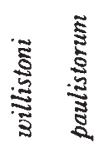 \\
\hline & 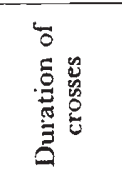 & 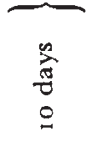 & $\begin{array}{l}2 \\
\frac{5}{5} \\
n \\
n\end{array}$ & 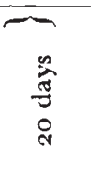 \\
\hline
\end{tabular}


paulistorum males $(t=2.33 ; \quad \mathrm{P}<0.02)$ which clearly demonstrate a decrease of isolation with time. This is not observed when the males are willistoni. Hence either paulistorum males increase their activity in the periods studied or willistoni females lose their discrimination against these males. According to Spieth (1952) D. paulistorum males "seem identical to willistoni in their behaviour, but the $D$. paulistorum female differs from willistoni female". Furthermore, Spieth suggests a more aggressive behaviour on the part of paulistorum females compared with the relatively passive willistoni females. The fact that Levene coefficients (table I) are less affected by changes in the length of time the flies are together than are other isolation indexes reinforces the significance of the results obtained.

The total sexual isolation between the two strains as measured by the coefficient of joint isolation $\left(\mathrm{K}_{1}\right.$ and $\mathrm{K}_{2}$, table $\left.\mathrm{I}\right)$, decreases to a significant extent $(\mathrm{P}<0.05)$ with time. Nevertheless it is noticeable at table $I$ that after 20 days even the homogamic insemination was not complete. Burla et al. (I 949) observed that for a period of about 10 days after mating willistoni males $\times$ (willistoni + paulistorum) there is Ioo per cent. of homogamic insemination, but paulistorum males $\times$. (paulistorum + willistoni) showed 89 per cent., which is comparable to our finding of 84.62 per cent. for 20 days. Dobzhansky and Koller (1938) found four to five days to be enough for almost all females to become impregnated in the homogamic crosses between $D$. pseudoobscura and miranda in multiple choice tests.

On the experimental conditions the gene flow goes chiefly from paulistorum to willistoni and increases significantly with time $(\mathrm{P}<0.05)$ as expected by the results with the other coefficients.

Burla et al. (1949) found no heterogamic insemination in either the crosses of willistoni or paulistorum males in multiple choice tests. Yet, in tests without choice they found 5.7 per cent. of the 69 females inseminated by paulistorum which is not significantly different from our results for Io days period $\left(\chi^{2}=0.23 ; \mathrm{P}<0.70\right)$, with the same kind of crosses. On the other hand, Burla et al. (1949) found that paulistorum males inseminated $5 \mathrm{I} \cdot 3$ per cent. of the 230 willistoni females in the same period. This is significantly higher than we find in the same type of crosses $\left(x^{2}=33.7 ; \mathrm{P}<0.005\right)$. Unfortunately, Burla et al. did not give the geographic origin of the strains used. But this lack of sexual isolation might well be explained if their paulistorum and willistoni samples were originally from allopatric populations. According to the results here reported and those of Dobzhansky, Ehrman and Pavlovsky (1957) there is more sexual isolation among sympatric populations of two species than among the allopatric ones, as expected on theoretical grounds. We may conclude also that this holds true for paulistorum males only.

In this connection it is interesting to mention that Dobzhansky and Spassky (1959) discovered a complex cluster of subspecies or species in statu nascendi formed by $D$. paulistorum. The Andean-South 
Brazilian group appeared to be heterogeneous ; these facts emphasise the possibility of finding further sexual isolation differences among paulistorum populations when tested with willistoni. According to the excellent studies of Ehrman (1960a, I96ob, I961) on paulistorum " matings between the subspecies succeed much less frequently than do those within a subspecies". The genic basis of sexual isolation is apparently "fostered by factors distributed over all the chromosomes ", these polygenes having additive effect that add up to a nearly complete bar to crossing between the subspecies.

\section{FERTILE HYBRIDS BETWEEN DROSOPHILA WILLISTONI AND DROSOPHILA PAULISTORUM}

Ten males and ten virgin females were aged separately for three days before crossing in vials $(30 \times 80 \mathrm{~mm}$.). A total of roo females, willistoni or paulistorum, was crossed this way with equal numbers of males of the other species. Every third day culture transfers were made until the last female died. This occurred after about 45 days giving approximately 150 cultures for each type of cross, which were carefully observed for larvæ, pupæ and adults. The $F_{1}$ hybrids obtained were handled with the same technique to study their fertility. Backcrosses were made to both parental species strains. A specially rich culture media was used (with soybean and maize flours, wheat germ, sugar and yeast), which probably improves the survival of the hybrids.

The crosses of $D$. willistoni male $\times D$. paulistorum female yielded few $F_{1}$ individuals, with a predominance of females. None gave an $F_{2}$. The $F_{1}$ hybrids were sterile when backcrossed to both parental species.

In contrast the reciprocal crosses, $D$. paulistorum male $\times D$. willistoni female yielded a greater number of $F_{1}$ hybrids, which were mostly fertile and produced a fairly numerous $F_{2}$. Surprisingly the $F_{1}-P_{1}$ backcrosses gave descendants readily only whe male or female $F_{1}$ hybrid were crossed with the paulistonum parental s min ${ }^{-} w$ offspring being obtained when $F_{1}$ males were backcrossed to willistoni females and none in backcrosses of $F_{1}$ females to willistoni males.

These results seem to indicate that the hybrids have a greater affinity with the paulistorum strain. A greater affinity between the $F_{1}$ hybrids and the male parental strain has also been observed in crosses of $D$. equinoxialis male (Tefé) $\times D$. paulistorum female (Florianopolis-72) and $D$. tropicalis male (Trinidad-330) $\times D$. tropicalis female (Palma) (Winge, r96r and unpublished data).

\section{SPERMATHECA AND HYPANDRIA OF THE TWO SPECIES AND OF THEIR HYBRIDS}

The spermathecæ and hypandria of the two species and of their hybrids were dissected under a stereomicroscope and the chitinous parts of the genitalia mounted in slides with Euparal and protected 
with coverslides. The spermathecæ were dissected in Drosophila saline solution, and mounted on slides with coverslides as usual. The drawings of fig. I were made by camera lucida.

The spermathecæ of the $F_{1}$ hybrids (paulistorum male $\times$ willistoni female) is clearly intermediate between those of the parents. The

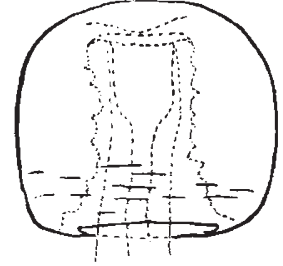

D. willistoni

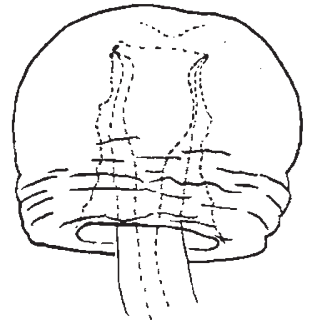

$F_{1}(\delta 0$. paulistorum $x$

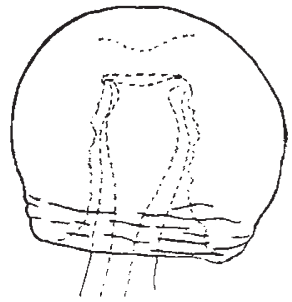

कD.willistoni)
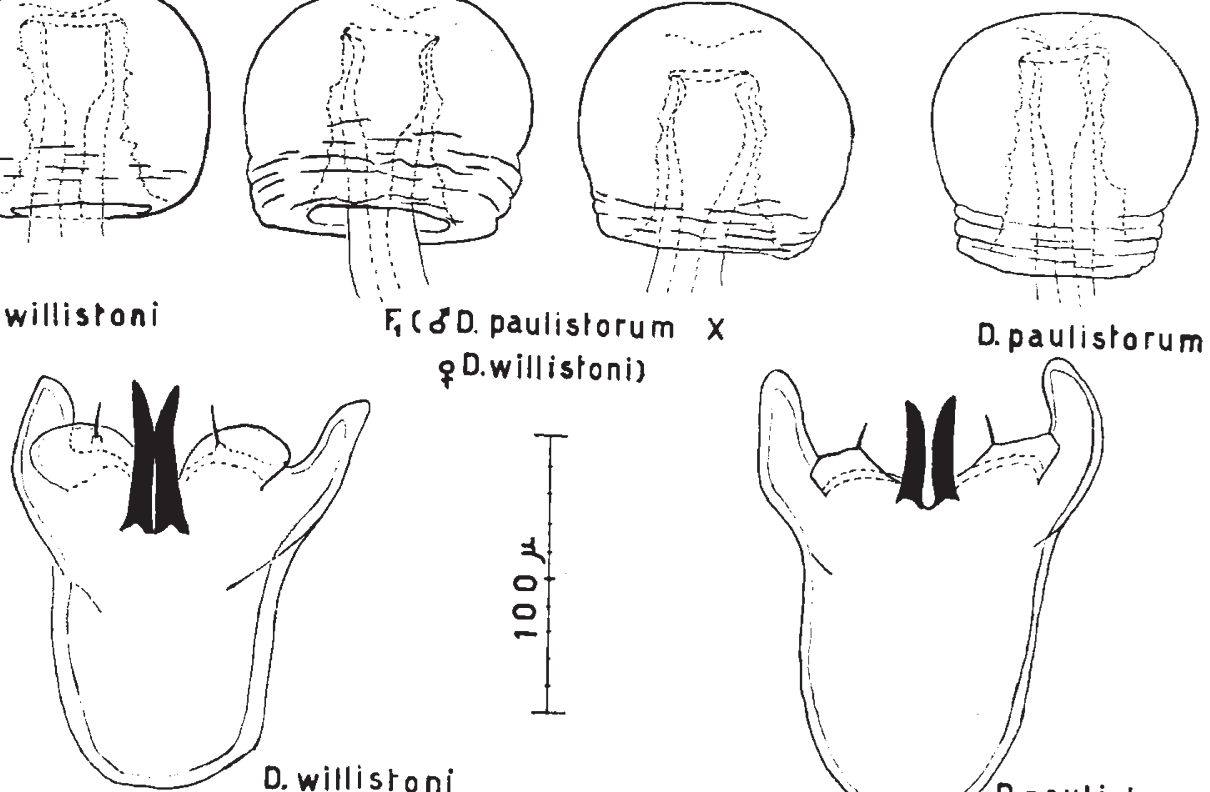

D. paulistorum
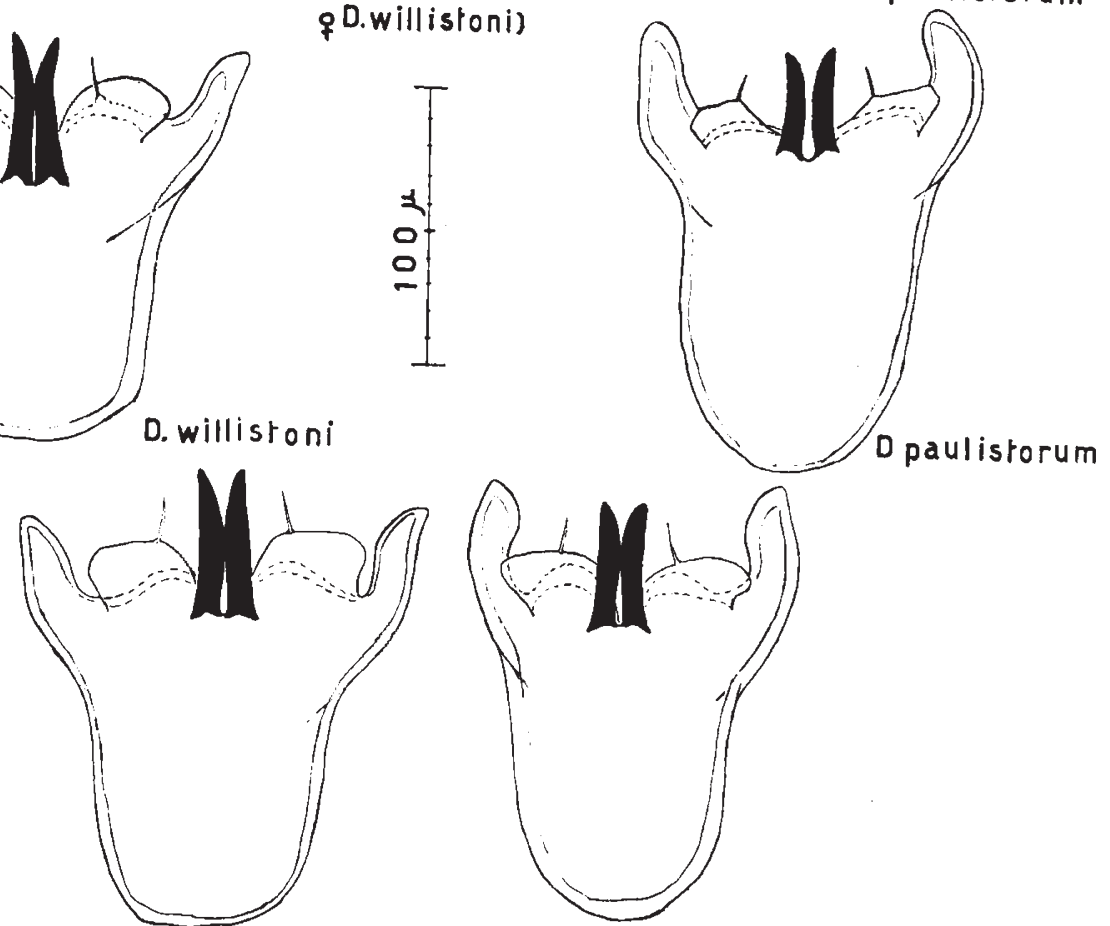

$F_{1}\left(\& D\right.$. paulistorum $x_{q}$ Dwillistoni)

Fic. I.-Spermathecr and hypandria of D. willistoni, D. paulistorum and of their hybrids.

general external shape varies more than the folds of the base which are always stronger than in willistoni and less conspicuous than in paulistorum. The canal uniting the spermatheca with the vagina is not cup-shaped as in willistoni and resembles more the vase-shaped type of equinoxialis rather than that of paulistorum itself (fig. I).

The hypandria in the genitalia of $F_{1}$ male hybrids also varied. The edges of the expansions, or lobes, are rounded in willistoni and 
angular in paulistorum. The hybrids vary greatly in this trait. In spite of this, in $F_{1}$ males, the small setæ are inserted in the edges of these lobes as in paulistorum. The two great teeth which have a lower insertion in willistoni than in paulistorum, are intermediate in the hybrids (fig. I).

Whatever the extent of the variation among the $F_{1}$ hybrids for these anatomical traits it is always possible to distinguish them from the parental species. This possibility was recognised by Cordeiro (1952) from studies of the inheritance of hypandrium shape between two contrasting races of paulistorum, one from Osório, Rio Grande do Sul, and the other from S. Paulo. These racial differences in the hypandrium lobes proved to be controlled by a single mendelian factor. This need not be the case among the two species here studied. Spassky (1957) also noticed that the male external genitalia of $F_{1}$ hybrids of $D$. willistoni $\times D$. insularis are intermediate.

\section{SUMMARY AND CONCLUSIONS}

Two strains, one of willistoni and another of paulistorum derived from inseminated females collected in the seashore rain forest of the north of Rio Grande do Sul State, have been studied extensively because of their unexpected ability to yield fertile hybrids between two species which are usually completely isolated.

Insemination tests, analysed statistically with the aid of Levene's (1949) isolation coefficients, demonstrated an increase in the acceptance of paulistorum males by the willistoni females with time. The reciprocal crosses do not show this behaviour. Under the experimental conditions, the genic flux goes from paulistorum to willistoni, according to Levene's formulæ.

Only a few sterile $F_{1}$ hybrids, have been obtained when willistoni males were crossed to paulistorum females; yet the reciprocal crosses yielded fairly numerous fertile $F_{1}$ s and $F_{2}$ s. The backcrosses $F_{1} \times P_{1}$ gave better results when mated to the male's parental species paulistorum.

These facts and the sex ratio deviation 3.3 males: I female observed in the $F_{1}$, suggests a maternal effect which has not yet been elucidated.

The intermediate morphology of most traits of the spermathecæ and hypandria of the hybrids between these species, corroborates the findings of Spassky (1957) and Cordeiro (1952). Nevertheless, the genetical basis of the observed traits need not be a single mendelian factor as it is among the races of paulistorum studied by Cordeiro.

This is the first recorded instance of hybrids between these two species. Cytological and genetic studies of other strains show that the affinities and hybrid production, as well as chromosome pairing, vary greatly even among strains from a single locality which, according to data to be published elsewhere, has a restricted population. 
Acknowledgments.-The authors wish to thank Miss Nena B. Morales for her interest and technical aid.

The collecting and laboratory expenses have been supported by The Rockefeller Foundation, The Conselho Nacional de Pesquisas and the University of Rio Grande do Sul.

\section{REFERENCES}

BURLA, H., DA CUNHA, A. B., CORDEIRo, A. R., DOBZHANSKY, TH., MALOgolowkin, C., AND PAVAN, C. 1949. The willistoni group of sibling species of Drosophila. Evolution, 3, 300-314.

CORDEIRO, A. R. 1952. Inheritance of variations in the male genitalia in Drosophila paulistorum. Amer. Nat., 84, 185-188.

DoBzHANSKY, TH. 1946. Complete reproductive isolation between two morphologically similar species of Drosophila. Ecology, 27, 205-21 I.

Dobzhansky, тн. 1951. Genetics and the Origin of Species. $\mathrm{x}+364$ pp. Columbia University Press, New York.

DOBZHANSKy, TH., eHRMAN, LEe, AND PAvlovsky, O. 1957. Drosophila insularis, a new sibling species of the willistoni group. Univ. Texas Publ., Genetics of Drosophila, 5721, 39-47.

DOBZHANSKY, TH., AND KOLLER, P. CH. 1938. An experimental study of sexual isolation in Drosophila. Biologischen Zentralblatt, $5^{8}, 589-607$.

DOBZHANSKY, TH., AND SPASSKY, в. 1959. Drosophila paulistorum, a cluster of species in statu nascendi. Proc. Nat. Acad. Sci., 45, 419-428.

EHRMAN, LEE. 196oa. A preliminary study of mating behaviour in Drosophila paulistorum. Amer. Nat., 94, 189-191.

eHRMAN, LEe. 196ob. The genetics of hybrid sterility in Drosophila paulistorum. Evolution, 14, 212-223.

EHRMAN, LEe. 196r. The genetics of sexual isolation in Drosophila paulistorum. Genetics, 46, 1025-1035.

LEVENE, H. 1949. A new measure of sexual isolation. Evolution, 3, 315-321.

MALogolowkin, CHANA. 1952. Sôbre a genitália dos "Drosophilidae" (Diptera). III. Grupo willistoni do gênero Drosophila. Rev. Bras. Biol., 12, 79-96.

MAYR, E. 1942. Systematics and the Origin of Species. Columbia University Press, New York.

SPASSKY, B. 1957. Morphological differences between sibling species of Drosophila. Univ. Texas Publ., Genetics of Drosophila 5721, 48-61.

SPIETH, н. T. 1952. Mating behavior within the genus Drosophila (Diptera). Bull. Am. Mus. Nat. Hist., 99, 395-474.

WINGE, HELGA. 1961. Relações interespecíficas no grupo críptico willistoni (Drosophila). Anais do II Congresso Brasileiro de Zoologia (196I) (in preparation).

WINGE, HELGA, AND CORDEIRo, A. R. I96o. Descoberta de uma ponte biológica entre Drosophila willistoni e paulistorum (Summ.) Ciência e Cultura, 12, 149. 